\title{
Introduction to the inaugural general issue of environment systems and decisions
}

\author{
Igor Linkov $\cdot$ James H. Lambert $\cdot$ Zachary A. Collier
}

Published online: 28 August 2014

(C) Springer Science+Business Media New York (outside the USA) 2014

On behalf of the Editorial Board, we are proud to present to our readers an issue that represents a milestone for Environment Systems \& Decisions. Since our inception in 2013, Environment Systems \& Decisions has published six thematic special issues, ranging in topics from sustainability to cybersecurity, and exploring analytic methods such as value of information. In these issues, published submissions have largely come from the active advertisement and solicitation from the members of the Editorial Board. However, this current issue represents the journal's first issue that is non-thematic and comprised entirely of general submissions.

This is encouraging for the future unsolicited contributors of Environment Systems \& Decisions. An increasing influx of high-quality, unsolicited research papers shows that the journal's readership is growing and its reputation is strengthening. The vision of the Editorial Board is a balance of special issues with issues comprised of general submissions. As the journal grows and matures, we are confident that the proportion of published articles from general submissions will continue to increase.

The articles contained within this issue are representative of the aims and scope of the journal as a whole. Articles in this issue explore a diverse range of topics, including ecosystem management, public health, and

I. Linkov $(\bowtie) \cdot$ Z. A. Collier

US Army Engineer Research and Development Center,

Vicksburg, MS, USA

e-mail: Igor.Linkov@usace.army.mil

Z. A. Collier

e-mail: Zachary.A.Collier@usace.army.mil

J. H. Lambert

University of Virginia, Charlottesville, VA, USA public policy issues. Methodologically, approaches such as risk analysis, multi-criteria decision analysis, and machine learning are being applied in this issue to various applications in industry, government, and the military.

First, the issue opens with three Perspectives articles covering a variety of topics. Linkov and Keisler (2014) open by comparing the nature of decision models with other types of models used in the environmental sciences, and how decision models can be useful in bridging some gaps left by traditional mechanistic and statistical models. Paul et al. (2014) then discuss an aspect of the green movement and sustainability, and they explore reasons why, despite ubiquitous calls for sustainability, there is disappointing progress on the environment. The third of the Perspectives articles looks at the history of Venice during the outbreak of the bubonic plague (Linkov et al. 2014). With a historical backdrop, lessons and principles for risk and resilience management are drawn which can be applied to infrastructures and systems of the modern era.

This issue continues with a number of original research articles. MacIntyre (2014) applies risk analysis and epidemiology to the recent outbreak of Middle East respiratory syndrome coronavirus in an attempt to characterize the nature of the source of the infections. Masetti and Calder (2014) describe a risk-based index approach that was developed to assess the risks of potentially polluting marine sites. Next, Birisan and Beling (2014) apply a multiinstance learning algorithm to image retrieval with the goal of filtering and processing images that will be of higher interest to users, thus reducing the cognitive burden caused by searching through large data sets. Mauelshagen et al. (2014) develop a contingency-based risk management model to protect the financial assets of a firm against medium-probability and medium-impact risks and discuss how it can supplement traditional insurance approaches. A 
case study is presented which focuses on a stakeholder engagement approach to understanding the ecosystem effects of recovery actions on the cottonwood community along the Missouri river (Burks-Copes and Kiker 2014). Vastveit et al. (2014) compare and contrast the regulatory regimes of Norway and Sweden to understand how riskbased information is used to facilitate policy decisions. Finally, Gorai et al. (2014) utilize fuzzy evaluation methods and the analytic hierarchy process to develop an air quality index and apply the method to a case study in India.

For energetic support and success of the journal to date, we would like to thank the Editorial Board, our capable reviewers who met the needs of a rapid production schedule, and the Springer editorial staff. Finally, we are pleased to announce upcoming special issues focused on climate change, nanotechnology, resilience, and more to be determined. We invite our readers and colleagues from academia, government, industry, and the military to continue to submit high-quality articles to Environment Systems \& Decisions, both for the special issues and for the issues that will be comprised mostly of general submissions.

\section{References}

Birisan M, Beling P (2014) A multi-instance learning approach to filtering images for presentation to analysts. Environ Syst Decis 34(3). doi:10.1007/s10669-014-9512-7
Burks-Copes KA, Kiker GA (2014) Uncovering lines of evidence hidden in complex problems: using conceptual models to inform ecosystem-based management of the Missouri River Cottonwoods. Environ Syst Decis 34(3). doi:10.1007/s10669-0149509-2

Gorai AK, Kanchan NA, Upadhyay A, Goyal P (2014) Design of fuzzy synthetic evaluation model for air quality assessment. Environ Syst Decis 34(3). doi:10.1007/s10669-014-9505-6

Linkov I, Keisler J (2014) Environment models and decisions. Environ Syst Decis 34(3). doi:10.1007/s10669-014-9515-4

Linkov I, Fox-Lent C, Keisler J, Sala SD, Sieweke J (2014) Risk and resilience lessons from Venice. Environ Syst Decis 34(3). doi:10.1007/s10669-014-9511-8

MacIntyre CR (2014) The discrepant epidemiology of Middle East respiratory syndrome coronavirus (MERSCoV). Environ Syst Decis 34(3). doi:10.1007/s10669-014-9506-5

Masetti G, Calder B (2014) A risk index methodology for potentially polluting marine sites. Environ Syst Decis 34(3). doi:10.1007/ s10669-014-9504-7

Mauelshagen CW, Pollard SJT, Owen D, Herdlhofer S, Firth P, McKenna J, Bingley N, Jenson P (2014) Protecting asset value and driving performance with a dynamic, risk-based contingency fund. Environ Syst Decis 34(3). doi:10.1007/s10669-014-9508-3

Paul A, Downton PF, Okoli E, Gupta JK, Tirpak M (2014) Does adding more lettuce make a hamburger truly green? A metaphor behind the green movement paradigm in designing cities. Environ Syst Decis 34(3). doi:10.1007/s10669-014-9507-4

Vastveit KR, Eriksson K, Njå O (2014) Critical reflections on municipal risk and vulnerability analyses as decision support tools; the role of regulation regimes. Environ Syst Decis 34(3). doi:10.1007/s10669-014-9510-9 